\title{
Traceability in the food-sector: the state of the art in a North Eastern Italian region
}

\author{
A. Payaro \& S. Busetto \\ Department of Innovation and Business Management, \\ University of Padua, Italy
}

\begin{abstract}
Product tracking and traceability are two key elements in supply chain management. In the sector of fruit and vegetables destined for fresh consumption, the management of product and information flows is particularly complex due to the high perishability of the product. Through a qualitative empirical analysis, this study evaluates the recourse to information and communication technology in the implementation of traceability, and highlights three main issues: product, organization and technology.

Keywords: traceability, information and communication technology, agri-supply chain.
\end{abstract}

\section{Fruit and vegetable supply chains}

In recent years, logistics has taken on a new dimension, no longer concentrated within companies, but rather extended to all the relationships between members of a supply chain. In particular, there is a growing awareness that the strategic goal of all chain members is joint value creation [7] and thus every stakeholder has to contribute to optimising value of the product or the service [9].

It is in this context that the concept of Supply Chain Management (SCM) developed. This concept takes into consideration all the members of the chain, from the supplier of raw materials to the end consumer and all the flows which cross it: product flow, information flow and finances flow [2]. Optimal supply chain management is a strategy which can guarantee a competitive advantage in the modern economy [3]. Furthermore, supply chain management is not only applicable to industrial contexts, but also to the agro-food sector. In the literature, the "agri-supply chain" is defined as the economic system which, in 
agro-food production, distributes value among the members, thus reinforcing cooperative mechanisms within the chain and developing incentives to assure the punctual production and distribution of the products.

According to the Agri-Chain Competence Center (ACC) [1] the development of supply chain management for fruit and vegetable products brings:

- improved profit margins thanks to the development of long term relationships between chain members

- $\quad$ increased knowledge of the market for primary producers (farmers), thanks to better information transfer;

- $\quad$ increased cooperation among members, which reduces product loss in storage and transport phases

- reduction in crossing times/time to market favouring increased food safety due to greater guarantee of product freshness

- full coordination of all members in the activation of marketing strategies aimed at promoting the products.

Facing challenges such as progressive globalisation and rapid changes in consumer demand is beyond the means of the single farm, but organised supply chains can assure more immediate responses to changes in the market.

The ACC suggests three general strategies for agri-supply chains to obtain competitive advantages

1) Chain differentiation

This refers to the forming of supply chains which respond to the demands of a specific sector of the market. Consumers are ever more demanding in their request for more product variety; to respond to this demand, production chains have to progressively differentiate and need to have a clear vision of the way the market is going.

2) Integral chain quality assurance

End consumers' choices are increasingly determined by a concern with standards of quality and food safety [8]. The development and implementation of quality assurance all along the production chain and the implementation of tracking and tracing systems mean that suppliers and customers can, respectively, supply and receive added product value [4].

3) Chain process realignment

The re-engineering of logistic operations within the supply chain has become a key factor. The reconfiguration of operations tends to identify and eliminate causes of inefficiency and develop a competitive advantage over competitors. The coordination of a chain can lead to a reduction in operational costs, improved production cycles, reduced transport and warehouse storage time. Chain-process realignment has been made possible by information and communication technology.

The aim of a supply chain is to allow the right product to reach the consumer in the agreed time, quantity and condition so that it serves the function it was planned for and meets the requirements of the people who use it. Fresh, perishable goods are problematic in that they impose greater constraints in the transport phase. The goods are to reach the consumer intact, not deteriorated, free of pathogens and suitably ripe. 


\section{Traceability in the fruit and vegetable supply chain}

After harvesting, most fruit and vegetables are destined either for fresh consumption or for processing. The fresh product reaches the consumer without changing in form or composition, while the processed product changes both form and composition [5]. The study looks at the supply chain of the fresh product, characterised by a distribution which has to guarantee a constant temperature. The supply chain is a branch of the agro-food system which allows the isolation and identification of operators and farms which produce and distribute a single product or of a family of products to the consumer [6].

In particular, among the various members of a supply chain, the study takes into consideration Producers' Organizations (POs) which have been recognised by the Ministry of Agriculture and Forestry in accordance with Regulation CE2200/96. This regulation recognises POs as an essential instrument for the management of fruit and vegetable production and for dealing with the agro-food market, to the advantage of the producers they represent. The aim of the study is to evaluate the feasibility of tracking and tracing systems in the fruit and vegetable supply chain. In this supply chain the Producers Organisations have direct contact with the farmers, upstream, while downstream they can distribute their products directly to the large distributors, to wholesale markets or producers' markets.

Tracking is a technical and organizational innovation, a technique for gathering and managing data to manage the information flow which accompanies the product flow from its point of origin to its point of consumption. The European Commission, with the publication of the White Book on 12 January 2000 on food safety, emphasised the need to bring the world of food production closer to that of the consumers through the application of assurance, communication, observation and vigilance systems connected to production techniques and knowledge of the food product. Traceability means "the ability to trace and follow a food, feed, food-producing animal or substance intended to be, or expected to be incorporated into a food or feed, through all stages of production, processing and distribution; (Regulation (EC) No 178/2002 art.3-15).

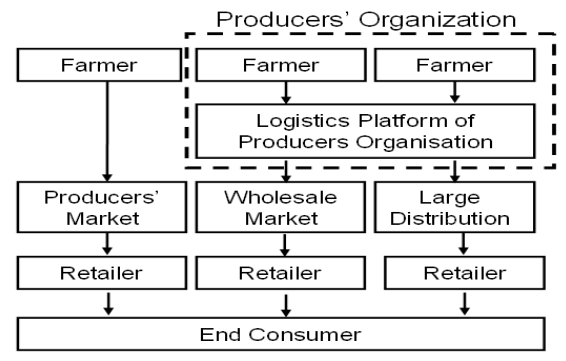

Figure 1: The fruit and vegetable supply chain.

On 1st January 2005, traceability as defined in articles 18 and 19 of Regulation (EC) No 178/2002 came into force, and its implementation 
presupposes product tracking. This means that it is necessary to be able to trace a product from the consumer back to its source, and to do this a tracking system is necessary. This system should be based on a combination of information, that is traces, which illustrate all the phases the product goes through from the moment it is harvested.

In this study, by analysing traceability, tracking is implicitly analysed at the same time. Chain traceability was originally to be implemented as a solution for safety risks. Subsequently the implementation of traceability was also found to generate a competitive advantage; in particular keeping track of a product along the whole chain means transparency regarding the provenance of a product and the treatments it has undergone, greater control over production processes to increase the efficiency of the chain and to provide the consumer with the assurance he/she is buying a product which respects current norms.

\section{The research}

From what has been said so far, there is clearly a need to recognise tracking and traceability as an instrument which can integrate and coordinate fresh fruit and vegetable supply chains. The following considerations apply to this sector in particular:

- $\quad$ the fruit and vegetable supply chain is extremely complex. Parameters such as the perishability of the product, the impossibility of freezing, the necessarily short time to market, the strong dependence on weather conditions which also influence the predictability of consumer trends, are all elements which condition the choices and strategies that can be applied to the chain.

- $\quad$ in the fruit and vegetable sector, the concept of tracking and tracing is of particular interest since application of the regulation CE178/200s in January 2005.

- the increased consumer demand for quality products encourages companies working in the fruit and vegetable sector to intensify the information flow which involves all members of the chain.

- at present, codification and collection of data and information have not been standardized.

A system that guarantees traceability presupposes enough quality information to univocally identify and track a product and the transformations it undergoes along the chain.

Producers' Organizations (POs) play a role of vertical coordination in that they manage and check the phases of concentration and marketing of the supply. Producers Organizations currently manage a system of supply chain integration by coordinating product and information flows from the producer to the consumer. This means that each Producer's Organization has developed its own tracking system. In order to plan a uniform and efficient tracking system it is necessary to collect and evaluate each project which has been developed, adopt the strong points and improve weak points, or define a system ex novo.

On the basis of the considerations presented, the aim of this study is to identify and understand the main issues involved in the creation of a product 
tracking and traceability system. Some of the main members of a fruit and vegetable supply chain were contacted and interviewed face to face or by telephone. The European Community believes that now more than ever the grouping of supply by Producers Organizations is an economic necessity to consolidate the position of producers in the agro-food market and to protect their interests in the face of the growing demand. Furthermore, Producers Organizations are seen to represent the fundamental elements of the Common Organization of Markets and contribute to reaching its objectives. The study therefore concentrated on the analysis of the main Producers Organisations present in the Veneto and looked particularly closely at the greatest challenges and cornerstones for the formulation of an action plan to implement projects aimed at integrating and standardizing information within the fruit and vegetable supply chain.

To understand the phenomenon an empirical, qualitative research method was used in the data collection phase, consisting of in-depth interviews with the managers of 7 of the 8 Producers' Organisations in the Veneto involved in fruit and vegetable production for fresh consumption. The research was carried out in three separate phases in order to evaluate the application of the 178/2002 Regulation: in June 2004, February 2005 and June 2005. The aim of having the interviews at three different times was to evaluate the attitude of the POs towards the changes they had to apply.

From the data gathered it emerged that the main reasons underlying the creation of tracking and traceability systems are the following:

- $\quad$ to make the production process more transparent for member farms;

- to check management of the quality and efficiency of production processes;

- $\quad$ to add value to the product on the market;

- $\quad$ to guarantee the collection of the data necessary for public bodies (ministry or region);

- $\quad$ to control food safety hazards;

- $\quad$ because of the increase in number of PO members.

While on the one hand the POs agreed on the importance of traceability, the instruments available to do this could not be considered satisfactory. While the organizations interviewed showed great interest in traceability before the regulation was implemented, afterwards they seem to have met only in part the requirements set in the regulations. Currently, therefore, the supply chain is not integrated enough for capillary and efficient product traceability. Below is a summary of the data gathered in the three research phases.

- $\quad$ Data gathered in June 2004. No PO had implemented a traceability system. The change is seen as a priority but there are not as yet any pilot projects. They say they are evaluating hypotheses as to how they can make the improvements.

- $\quad$ Data gathered in February 2005. Two POs out of 7 have improved their pre-existing information systems in order to have traceability within the company. There is no real supply chain integration and relations with customers and suppliers have not changed. 
- $\quad$ Data gathered in June 2005. 5 POs out of 7 have used internal resources to develop systems based on the printing of bar codes and the mapping of storage spaces. There can be said to be traceability within the company but relations with customers and suppliers have not changed.

\section{Critical issues in the fruit and vegetable supply chain}

An analysis of the interviews carried out reveals that the POs in the Veneto region have not set up a real traceability system. The reasons for this delay in complying with regulation CE 178/2002 can be determined by the existence of three critical issues which do not permit a standardization of the process. These are related to:

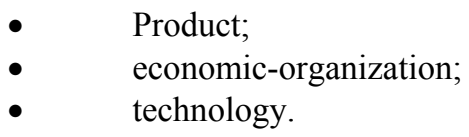

\subsection{Product}

The type of product influences the way it is grown, processed and stored with repercussions on the possibility of keeping a uniform track of information. It is not easy to code products; among environment-related factors fruit and vegetable type is one of the classification parameters. There are two families: plants from vegetable gardens and/or their fruits, and woody plants. The two families differ in several respects such as their production cycles, annual planning, the processes which the products undergo before they are ready for the market. These differences presuppose an information system which is capable of keeping track of everything that happens during the various production phases until they are purchased by the consumer. In addition to what we have already mentioned, there are also other parameters such as weight, colour, ripeness and calibre. As well as a coding system which correctly represents the product, it is necessary to record all the operations the product undergoes. The PO groups the products from the members. In the case of vegetable plants, the grower has to take care of the packing. The PO checks that no mistakes have been made during the phases of harvesting or packing, and when necessary replaces the packaging which does not conform to customers' requirements.

In the case of fruit from woody plants, producers deliver the picked fruit to the POs who take care of the preparation and packaging. This means that it is possible that goods from different producers are mixed in the preparation and calibration phases. The mixing occurs when producers deliver quantities that are too small to fill a loading unit, such as a pallet. Mixing means putting together goods which are no doubt identical in terms of quality, appearance, ripeness and size, but different in terms of the treatment received while growing.

\subsection{Economic-organizational}

The difficulty of adequately managing the calibration phase for traceability not only depends on the product, but also on a factor which is definitely 
organizational. If the quantities delivered to the POs were large enough to constitute a complete loading unit, there would be no problem of traceability. However this is hardly ever possible as agriculture in the Veneto is very highly fragmented with a myriad of small farmers.

To resolve this problem the system should be reorganised so that treatments carried out on the goods by different producers are the same. This coordination would allow the mixing of products from different farms, keeping the information about "the field" and without precluding the possibility of optimizing transport in the phases after preparation and packaging.

The field log book is still the main instrument used to record what is done to the produce. The organizational change requires producers to use information and communication technology to record information about the field log book. However other information about processes after growing, such as harvesting and delivery, are still recorded on paper. The move to digital recording of information cannot take place rapidly because of the lack of IT skills among producers.

Another organisational problem regards the codification and decodification standards which are used to record data, as well as the structures which are to store the data. Who will be responsible for managing the data-warehouse and for creating a standard for the transfer of information? In fact there is currently no member in the supply chain (such as, for instance, a chain leader) who can take on such responsibility, that is to manage a system of traceability, organize product flows, take care of product identification, manage the data and process documentation. In Certification of Supply Chain Traceability (UNI) and EUREP GAP certification (Euro-Retailer Produce Working Group, Good Agricultural Practice) farms in the supply chain are specifically asked to make a strict agreement between the chain leader and the other nodes.

Table 1: $\quad$ Information to manage as specified in production guidelines.

\begin{tabular}{|l|l|}
\hline Producer & Code of identification \\
\hline Product & Type of product (name of product) \\
& Name of variety \\
& Quantity and date delivered \\
& Category and calibre \\
& Hygienic-sanitary characteristics \\
& Treatments carried out \\
\hline Customer & Customer code \\
& Article sold \\
& Number and weight of items \\
\hline
\end{tabular}

In the research study there were some cases of POs which were more organised and characterised by a true corporate style. In these cases, with recourse to certification, company processes are optimized and, through the setting out of production regulations the marketed products are given increased quality. Certification adds value to the product guaranteeing its safety and wholesomeness through the management and control of the preparation phases. 
In accordance with the guidelines which have been developed, data about the grower, type of product and customer are collected. This does not mean that a traceability system involving all chain members, from the producer to the end consumer, can be formed on this basis, since the farms involved are only those associated within the POs.

Finally, the lack of a common strategy among all chain members makes immediate implementation of traceability difficult. The approaches developed by the different POs analysed are all different both in terms of the type of data that is gathered, and how it is gathered.

In short, some traceability projects were found, but the only aim of the systems developed is to resolve the POs internal requirements, such as estimation of the payment due to the producer/ member.

\subsection{Technology}

The technological issue is the fact that no system based on information and communication technology has been set up in the chain to gather information which defines the characteristics of the product batch.

The survey carried out highlights this lack of computerization in managing field log books which leads to a loss of data which would be useful in obtaining greater control of the chain. This shortcoming is due to a still not very widespread computer literacy in producers and the elevated cost of training staff, as perceived by producers.

While subjects upstream from the POs lack information systems, our survey revealed that some POs are equipped with personalised software solutions for recording data of what goes in and out of the warehouse. The personalization of systems creates problems of inter-communicability and sharing of information. In practical terms this means it is impossible to analyse and compare data, not just regarding the profitability of each member, but also for the total control of processes coming in and going out.

The general problem encountered in POs in the Veneto region regards the use of product codes which are not shared, but developed within the organizations themselves. This problem regards not only the Veneto region, but the whole of Italy and in practice means the following are still lacking:

- $\quad$ uniform names for fruit and vegetable products;

- ratification of the terminology and definitions of products and their characteristics;

- $\quad$ standardization of product identification codes.

The following figure compares the various phases of the vegetable production cycle with data which should be recorded (tracked) and the way in which the information related to each phase is currently treated.

As regards documentation, there can be said to be three different types:

- the sticky label: stuck on the outside of the packaging, integrated in the packet or firmly stuck to it, it has to contain information in a legible and undeletable form and must be visible on the exterior. 
- $\quad$ paper form: these are paper documents filled in by hand which are not stuck on to the packets but can accompany the product during the production cycle. These documents are subject to deterioration, loss, damage.

- $\quad$ in digital format: part of the vaster range of technologies for automatic identification (Auto ID): bar-codes and identification systems which use radiofrequency signals (RFID).

The bar code is a symbology or alphabet for codifying information in such a format that it can be automatically captured using suitable optical readers. The RFID identification system which uses radiofrequency signals, based on a microchip (Tag) placed on the product, has some undeniable advantages when compared to bar codes:

- $\quad$ it is the only system which can exchange information in two directions: not only from the Tag to the reader, but also from the reader (in this case writer) to the Tag, modifying the data contained.

- $\quad$ it is resistant to external agents and thus is suitable for use in hostile environments (dirty, humid, high temperature).

- $\quad$ it has a memory store and thus can transport a considerable amount of data.

- $\quad$ it can be read from a distance and doesn't necessary have to be visible.

- $\quad$ the reading system is very efficient and more than one Tag can be read at a time.

As can be seen in the image, the information is gathered, memorized in different formats and sometimes is not transferred from one phase to the next in the production process, thus frustrating the possibility of tracing the product. Furthermore, some information is gathered and managed only for internal reasons and is not shared with other members of the chain.

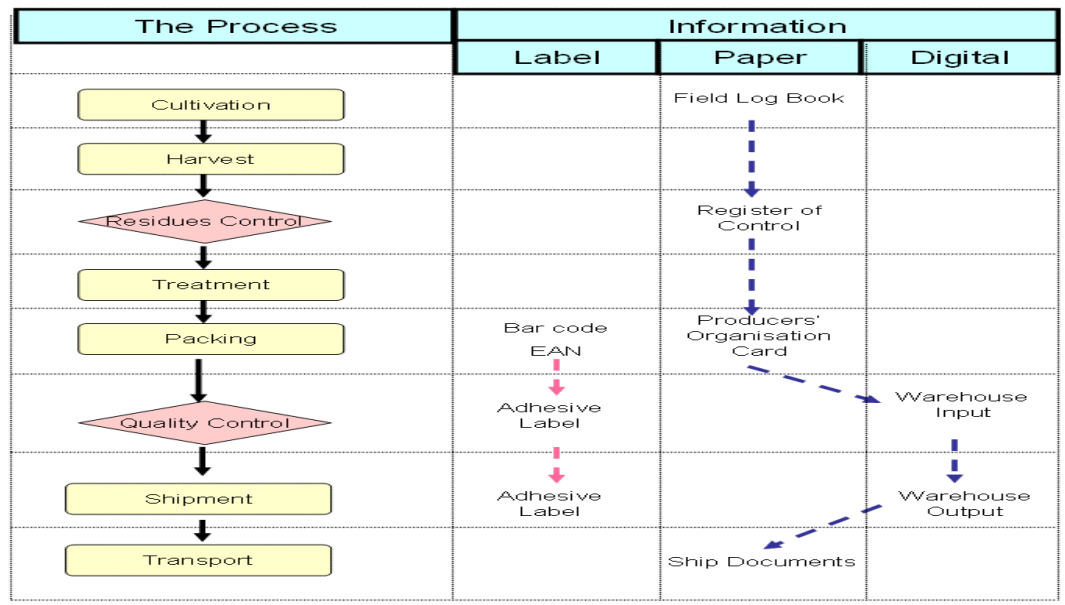

Figure 2: $\quad$ Production process and tracked data. 


\section{Conclusions}

The picture that emerges from the fruit and vegetable sector in the Veneto as regards traceability is not homogeneous at all, either in terms of intentions or of technology. It is, however, characterized by some general internal issues relating to:

- the need to make control procedures and internal management of production systems more efficient in the phases of transformation/processing to avoid losing information and traces of the product.

- lack of computer skills in production areas, that is information regarding "the field" and the consequent decision not to adopt technology for automatic identification: too expensive from the point of view of staff training, too much of a burden from an organizational point of view;

- difficulty in extending a corporate standpoint to farmer members which would facilitate the implementation of vertical integration systems as well as tracking/traceability systems.

Alongside internal issues are those which on the supply chain level prevent the development of traceability systems. The mere desire of the organization to control its own processes, as it would be worth doing from a business point of view, would lay the foundations for traceability; but this is not to say that it would be possible to construct, on this basis, a supply chain traceability system which involved all members, from the producer to the end consumer.

\section{References}

[1] Agri Chain Competence center, Chains on the move: structural change in the agri food chains, Paper presented to the Leaders Challenge Conference, Red Deer, Canada, 1997.

[2] Caputo M., Mininno V., Rescinniti R., "Integrazione logistica, interna e verticale, nella distribuzione dei beni di largo consumo", Economia e Management, No. 1, 1996.

[3] Christopher M., Logistic and supply chain management: strategies for reducing cost and improving service, Prentice Hall, 1998.

[4] Jongen W.M.F., Meulenberg M.T.G., Innovation of food production systems, product quality and consumer acceptance, Wageningen: Wageningen Pers, 1998.

[5] Malassis L., L'économie agroalimentaire , economie de la consommation et de la production agroalimentaire, Edition Cujas, Paris, 1979.

[6] Morvan Y., L'économie industrielle et la filière, ADEFI, L'analyse de filière, Economica, Paris, 1985.

[7] Pilotti L., Rullani E., 'Evoluzione e innovazione nelle forme distributive: doppia elica o servuction?", Commercio, No. 43, 1991.

[8] Ross J.E., Total quality management, Kogan Page, 1994.

[9] Varaldo R., Dalli D., "Le relazioni strategiche tra industria e distribuzione", Sinergie, No. 19, 1989. 